\title{
ANATOMIA DA MADEIRA DE TETRORCHIDIUM RUBRIVENIUM POEPP. \& ENDL. (EUPHORBIACEAE) ${ }^{1}$
}

\author{
ROSANA GUMA ${ }^{2}$ TALITA BALDIN ${ }^{3}$ LUCIANO DENARDI $^{4}$ CLÓVIS ROBERTO HASELEIN $^{5}$ \\ JOSÉ NEWTON CARDOSO MARCHIORI ${ }^{6}$
}

\begin{abstract}
RESUMO
É descrita a estrutura anatômica da madeira de Tetrorchidium rubrivenium Poepp. \& Endl., com base em material procedente do Rio Grande do Sul. Dos caracteres observados, salientam-se: material lenhoso composto principalmente de fibras e raios, seguido de vasos e parênquima axial; anéis de crescimento indistintos; porosidade difusa; vasos arredondados, solitários e em múltiplos radiais; placas de perfuração simples; parênquima apotraqueal difuso; raios heterogêneos, frequentemente fusionados; e fibrotraqueoides não septados, curtos, de paredes delgadas a espessas.
\end{abstract}

Palavras-chave: Anatomia da Madeira, Crotonoideae, Euphorbiaceae, Tetrorchidium rubrivenium.

\section{ABSTRACT}

[Wood anatomy of Tetrorchidium rubrivenium Poepp. \& Endl. (Euphorbiaceae)].

The wood structure of Tetrorchidium rubrivenium Poepp. \& Endl. is anatomically described, based on material from Rio Grande do Sul State, Brazil. The following characters should be highlighted: diffuse-porous wood, composed mainly by fibers and rays, followed by vessels and axial parenchyma; indistinct growth rings; round solitary and radial multiple vessels; simple perforation plates; apotracheal-diffuse axial parenchyma; heterocellular rays, often fused; and short non-septate fibertracheids, with thin to thick walls.

Keywords: Crotonoideae, Euphorbiaceae, Tetrorchidium rubrivenium, Wood Anatomy.

\section{INTRODUÇÃO}

Em virtude dos avanços em estudos filogenéticos dos últimos anos, muitas famílias botânicas foram retrabalhadas, caso das Euphorbiaceae, das quais segregaram-se as Phyllanthaceae, Putranjivaceae e Picrodendraceae. Atualmente, a família inclui 222 gêneros e cerca de 6.100 espécies de árvores, arbustos, lianas e ervas, geralmente latescentes, por

1 Recebido em 15/06/2014; aceito em 24/10/2014.

2 Engenheira Florestal, Mestre pelo Programa de Pós-Graduação em Engenharia Florestal, Universidade Federal de Santa Maria.rosana_guma@yahoo.com.br

3 Engenheira Florestal, Mestranda do Programa de PósGraduação em Engenharia Florestal, Universidade Federal de Santa Maria. talita.baldin@ hotmail.com

4 Engenheiro Florestal, Professor Adjunto, Dr. Departamento de Ciências Florestais, Universidade Federal de Santa Maria. lucianodenardi@yahoo.com.br

5 Engenheiro Florestal, Professor Adjunto, Dr. Departamento de Ciências Florestais, Universidade Federal de Santa Maria. clovis.haselein@ufsm.br

6 Engenheiro Florestal, Professor Titular, Dr. Departamento de Ciências Florestais, Universidade Federal de Santa Maria.marchiori@pq.cnpq.br vezes suculentas e de aspecto cactóide, distribuídas, principalmente, em regiões tropicais da América e África (Judd et al., 2009, Souza \& Lorenzi, 2008).

No Brasil encontram-se cerca de 70 gêneros e 1.000 espécies, o que torna a família uma das mais numerosas e taxonomicamente complexas da flora nativa (Souza \& Lorenzi, 2008).

Sob o ponto de vista econômico, a família apresenta espécies valiosas, como a seringueira (Hevea brasiliensis), principal fonte de borracha natural, bem como espécies ricas em óleos (Aleurites molucana, A. fordii), ceras e gorduras vegetais (Judd et al., 2009), além de plantas de interesse ornamental.

De acordo com Webster (1994), o gênero Tetrorchidium insere-se na subfamília Crotonoideae e compreende cerca de 20 espécies, predominantemente neotropicais, salientando-se Tetrorchidium rubrivenium Poepp. \& Endl., o popular canemaçu, bauna, peroba-d'água-amarela, pau-branco, embirão ou café-com-leite. 
Tetrorchidium rubrivenium distribui-se do México à Venezuela, Peru e Brasil (Backes \& Irgang, 2004). Sua existência foi originalmente descrita por Poeppig \& Endlicher (1845), a partir de material oriundo de floresta do leste do Peru, salientando a maior ocorrência na região leste do país. No Brasil, Backes \& Irgang (2004) referem sua ocorrência desde a Amazônia até o Rio Grande do Sul, encontrando-se, neste estado, na região do Alto Uruguai, ao norte do Rio Ijuí (Reitz et al., 1988) e, notadamente, no Parque Estadual do Turvo, (Ruschel et al., 2005).

De acordo com Reitz et al. (1988), trata-se de árvore de até $25 \mathrm{~m}$ de altura e $80 \mathrm{~cm}$ de diâmetro à altura do peito, de fuste alto, e densa folhagem verde-escura. As folhas, simples e em filotaxia alterna, apresentam duas glândulas eretas no pecíolo. Backes \& Irgang (2004) referem que o canemaçu possui bom desenvolvimento em vegetação secundária alterada, podendo ser uma alternativa viável para a recuperação desses ambientes. A madeira é considerada leve $\left(0,46 \mathrm{~g} / \mathrm{cm}^{3}\right)$, de superfície ligeiramente áspera ao tato, e coloração branco-amarelada a amarelo-clara, sem odor e gosto distintos (Reitz et al., 1988; Lorenzi, 2009).

São notavelmente escassas as informações sobre as espécies do gênero Tetrorchidium, sobretudo do ponto de vista estrutural. A descrição anatômica de $T$. rubrevivenium, neste sentido, visa a preencher uma lacuna no conhecimento científico da família Euphorbiaceae.

\section{REVISÃO DE LITERATURA}

A anatomia das Euphorbiaceae apresenta grande variabilidade devido à diversidade de hábitos vegetais e ambientes ocupados por suas numerosas espécies (Mecalfe \& Chalk, 1972). Record \& Hess (1949) relacionam, para a família: poros em múltiplos, com tendência a alinhamento radial; vasos com placas de perfuração simples; pontoações intervasculares alternas; espessamentos espiralados, ausentes; raios heterogêneos, finos e inconspícuos, usualmente unisseriados; parênquima axial reticulado ou em faixas concêntricas; fibras geralmente mui- to longas, com pontoações simples ou aréolas reduzidas, de paredes finas a muito espessas, comumente gelatinosas e raramente septadas; canais radiais, presentes em muitos gêneros; e cristais frequentes em raios, no parênquima axial ou em ambos.

Para as Crotonoideae, subfamília à qual se insere o gênero em estudo, Metcalfe \& Chalk (1972) citam os seguintes caracteres anatômicos: porosidade difusa; vasos em múltiplos radiais de 2-4 ou mais numerosos, de diâmetro médio $(50-290 \mu \mathrm{m})$, e frequência de 10 poros $/ \mathrm{mm}^{2}$ (de $4-150$ poros $/ \mathrm{mm}^{2}$ ); placas de perfuração simples; pontoações intervasculares médias a grandes $(4-16 \mu \mathrm{m})$, muitas vezes de formato irregular; pontoações raio-vasculares grandes e alongadas (frequentemente escalariformes), ou semelhantes às intervasculares; elementos vasculares de comprimento médio a moderadamente curto; parênquima abundante, apotraqueal, com células esparsas ou faixas contínuas de 1-2 células de largura; séries parenquimáticas de 8 células ( 4 em alguns gêneros); raios com 2-3 células de largura ou exclusivamente unisseriados, por vezes com 4-5 células de largura; raios marcadamente heterogêneos, frequentemente com 10 ou mais fileiras marginais de células eretas e mais de uma parte multisseriada por raio, por vezes com espaços intercelulares; fibras de paredes finas a moderadamente espessas, de comprimento médio a moderadamente curto, e com pontoações simples ou aréolas pequenas, por vezes distintas; e tubos laticíferos ocasionais, nos raios.

Para o gênero Tetrorchidium, não foram encontradas referências sobre a estrutura anatômica. No caso de outros gêneros ou espécies autóctones, recomendam-se: Barros \& Callado (1997), Barros et al. (2001; 2003), Marchiori (2000), Marchiori et al. (2009; 2010) e Siegloch et al. $(2011,2012)$.

\section{MATERIAL E MÉTODOS}

Os exemplares de Tetrorchidium rubrivenium utilizados no presente estudo provém de 
uma floresta natural do município de Vale do Sol, Rio Grande do Sul. A partir da seleção de um indivíduo adulto, em boas condições fitossanitárias, foram coletadas amostras de madeira, e material botânico fértil para a confecção de exsicatas, anexadas, respectivamente, na Xiloteca e Herbário do Departamento de Ciências Florestais da Universidade Federal de Santa Maria sob o número 6138.

Para o estudo anatômico do lenho, retirouse um disco de madeira do tronco a $1,3 \mathrm{~m}$ de altura. Do material lenhoso foram extraídos três corpos de prova $(3 \times 3 \times 3 \mathrm{~cm})$ da parte mais externa, próxima ao câmbio vascular, orientados para obtenção de cortes nos planos transversal, longitudinal radial e longitudinal tangencial. Um quarto bloquinho foi também retirado, com vistas à maceração.

O preparo de lâminas histológicas seguiu a técnica padrão (Burger \& Richter, 1991): após fervura em água (9 horas), os corpos-de-prova foram seccionados em micrótomo de deslize, regulado para obtenção de cortes com espessura nominal de $20 \mu \mathrm{m}$, coloridos com safranina e azul-de-astra, desidratados em série alcoólica crescente $(30 \%, 50 \%, 75 \%, 90 \% 90 \%$, duas vezes álcool absoluto), e passagem em xilol. No preparo de lâminas permanentes, usou-se "Entellan" como meio de montagem. Para a dissociação do tecido lenhoso, seguiu-se o método Ácido Nítrico-Acético (Barrichelo \& Foelkel, 1983); a pasta foi colorida com safranina $1 \%$ e, na montagem de lâminas, usou-se a mesma resina anteriormente referida.

A descrição qualitativa do lenho foi baseada nas recomendações do IAWA Committee (1989). A determinação da fração dos diferentes tecidos foi obtida com um contador de células, segundo a metodologia proposta por Marchiori (1980).

Todas as medições e contagens foram feitas em microscópio LEICA DM 1000, com ocular graduada, no Laboratório de Anatomia da Madeira da UFSM/CESNORS. As fotomicrografias da madeira foram obtidas em microscópio Olympus CX-40, no Laboratório de Anatomia da Madeira da Universidade Federal do Paraná (UFPR).

No texto descritivo, os dados quantitativos das características anatômicas referem-se a média (x) e desvio padrão (s), seguido pelos valores mínimo e máximo observados.

\section{DESCRIÇÃO ANATÔMICA}

Aspectos gerais: tecido lenhoso constituído principalmente de fibras e raios, que correspondem a $45 \%$ e $33 \%$ do total respectivamente; os $22 \%$ restantes estão distribuídos entre vasos e parênquima axial, em porcentagens quase iguais. Anéis de crescimento indistintos.

Vasos: arredondados e ovais (Figura 1B), de $133 \pm 34(88-223) \mu \mathrm{m}$ de diâmetro, em distribuição difusa. Poros solitários e em múltiplos radiais, por vezes em múltiplos racemiformes (Figura 1A), com frequência de $8 \pm 3(4-12)$ vasos $/ \mathrm{mm}^{2}$. Elementos vasculares de $1043 \pm 295$ (450-1600) $\mu \mathrm{m}$ de comprimento, com apêndices em ambas ou em apenas uma das extremidades. Placas de perfuração simples, oblíquas. Espessamentos helicoidais, tiloses e depósitos, ausentes. Pontoações intervasculares alternas, arredondadas ou poligonais $(15 \pm 2,5(13-20)$ $\mu \mathrm{m})$, com aberturas lenticulares inclusas, horizontais ou oblíquas, frequentemente cruzadas em "x", no par. Pontoações parênquimovasculares e raio-vasculares, semelhantes entre si; arredondadas, alongadas ou angulares, simples ou, mais comumente areoladas, com aberturas inclusas, lenticulares ou com abertura relativamente grande (Figura 1D, F).

Parênquima axial: apotraqueal difuso, menos frequentemente paratraqueal escasso (Figura $1 \mathrm{E})$, contrastante com as fibras em plano transversal devido à menor espessura da parede celular. Séries parenquimáticas de $3-7$ células, com $978 \pm 257(500-1440) \mu \mathrm{m}$ de altura e $42 \pm 12,5(25-80) \mu \mathrm{m}$ de largura.

Raios: heterogêneos, com células procumbentes, quadradas e eretas (Figura 1C), e frequência de $11 \pm 1,6(8-13)$ raios $/ \mathrm{mm}$. Os unisseriados, correspondentes a $50 \%$ do tecido, 

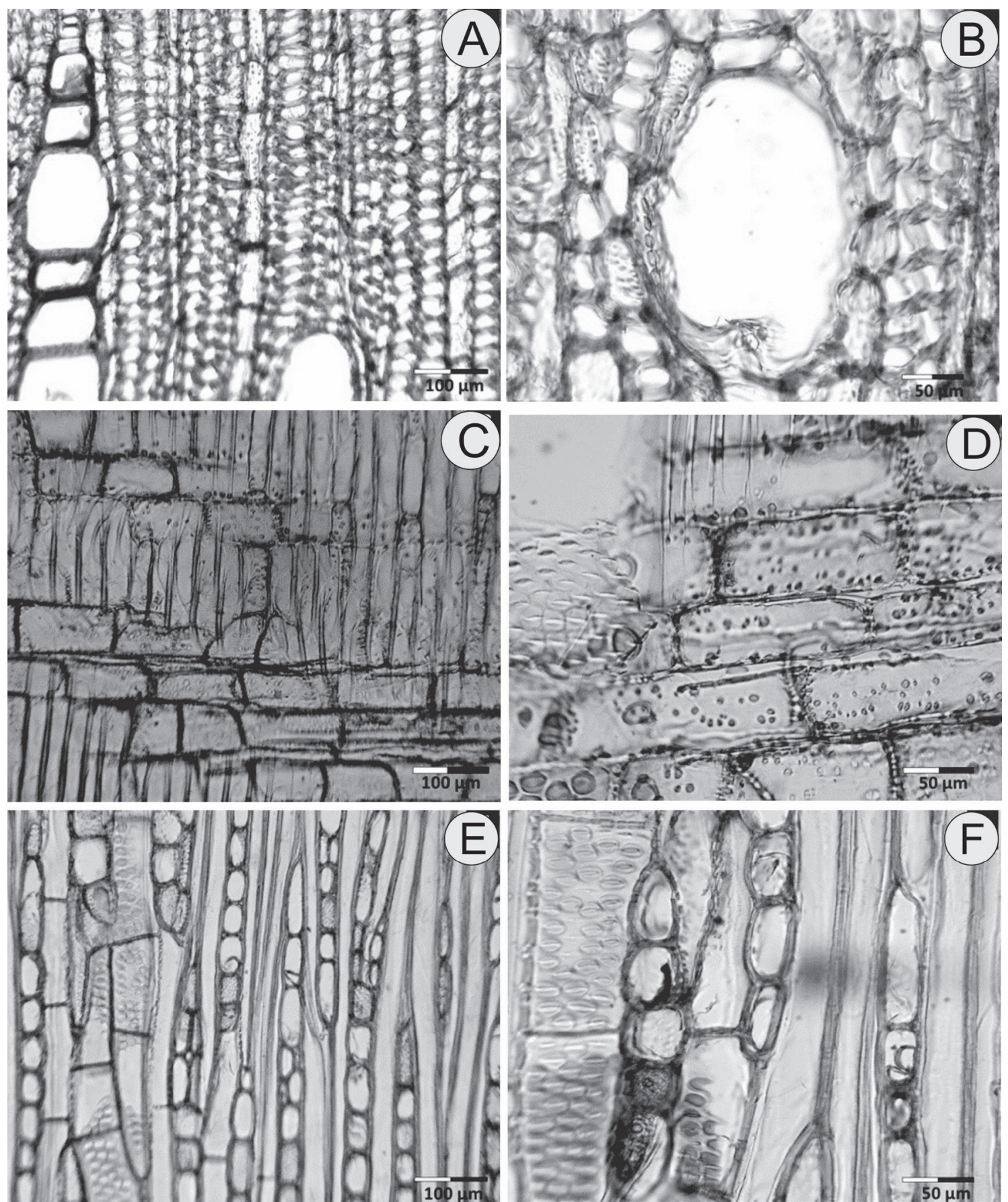

FIGURA 1: Aspectos anatômicos da madeira de Tetrorchidium rubrivenium. A - Seção transversal, mostrando poros em múltiplos radiais. B - Poro arredondado, em seção transversal. C - Raio heterogêneo, com células procumbentes, quadradas e eretas (seção longitudinal radial). D - Aspecto de pontoações raio-vasculares (seção longitudinal radial). E - Raios unisseriados e séries de parênquima axial, em seção longitudinal radial. F - Pontoações intervasculares (a esquerda) e parênquimo-vasculares (mais ao centro), em seção longitudinal tangencial. 
apresentam, normalmente, apenas células eretas, ou uma mistura de quadradas e eretas (Figura 1E). Os multisseriados, predominantemente bisseriados $(45 \%)$ e trisseriados $(4,7 \%)$, raro tetrasseriados $(0,33 \%)$, reúnem numerosas células procumbentes no centro, e 1 - 4 fileiras de células quadradas e/ou eretas nas margens. Raios fusionados, frequentes; células envolventes, raras.

Fibras: do tipo fibrotraqueóide, nãoseptadas; curtas $(1476 \pm 403(770-2520) \mu \mathrm{m})$ e de paredes delgadas a espessas. Pontoações areoladas arredondadas, com abertura em fenda vertical exclusa na face radial, extremamente raras ou ausentes na face tangencial da parede. Espessamentos helicoidais, fibras gelatinosas, traqueóides vasculares e traqueóides vasicêntricos, ausentes.

Outros caracteres: canais intercelulares, canais celulares, floema incluso, células oleíferas, células mucilaginosas e máculas medulares, ausentes.

\section{ANÁLISE ANATÔMICA}

As principais características observadas no lenho de Tetrorchidium rubrivenium estão de acordo com as possibilidades estruturais relacionadas por Record \& Hess (1949) e Metcalfe \& Chalk (1972) para as Euphorbiaceae: poros solitários e em múltiplos radiais; elementos vasculares curtos; placas de perfuração simples; pontoações intervasculares alternas; parênquima axial seriado, em arranjo apotraqueal difuso e paratraqueal escasso; raios predominantemente heterogêneos; e fibras não septadas, de paredes muito finas.

O material em estudo também coincide com as características anatômicas descritas por Metcalfe \& Chalk (1972) para a subfamília Crotonoideae: pontoações intervasculares grandes, na maioria dos gêneros (de 4-16 $\mu \mathrm{m}$ ); pontoações raio-vasculares grandes e alongadas; parênquima apotraqueal com séries de 8 células; raios marcadamente heterogêneos, com 2-3 células de largura ou exclusivamente unisseriados; fibras de paredes finas a moderadamente espessas, de comprimento médio a mo- deradamente curto, e com pontoações simples ou aréolas pequenas, por vezes distintas.

Apesar de relativamente comuns na família, não foram observados canais intercelulares, cristais, sílica e fibras gelatinosas, no material em estudo. Nas Euphorbiaceae, segundo Record \& Hess (1949) e Metcalfe \& Chalk (1972), a presença destes detalhes anatômicos é frequente em espécies com fibras de paredes espessas, motivo pelo qual se justifica a ausência do caráter em $T$. rubrivenium, que tem fibras de parede delgada a espessa.

Embora mencionadas por Mennega (2005) para o gênero Tetrorchidium, não foram observadas células perfuradas de raio na espécie em estudo. A presença de tubos lactíferos, embora frequente na subfamília, também não foi observada, corroborando informações do mesmo autor.

As séries do parênquima axial, compostas de 3-7 células, incidem com o descrito por Mennega (2005) para as Crotonoideae. Quanto à ocorrência de parênquima predominantemente apotraqueal, o canemaçu assemelha-se ao descrito para Joannesia princeps e Alchornea triplinervia (Mainieri \& Chimelo, 1989).

Com relação ao comprimento de fibras, os valores encontrados aproximam-se das demais espécies de Crotonoideae, tais como Colliguaya brasiliensis (Siegloch, 2011), Croton dracunculoides e Croton pycnocephalus (Siegloch, 2013).

Tetrorchidium rubrivenium apresenta 50\% dos raios unisseriados e $45 \%$ de bisseriados, valores que divergem do apontado por Mainieri \& Chimelo (1989), que consideram raríssimos os raios bisseriados na espécie. No que diz respeito à frequência de raios, todavia, os valores são semelhantes. Os autores indicam valores iguais para Chaetocarpus sp., outra espécie da família. A mesma frequência de raios é descrita por Marchiori et al. (2010) para Sapium glaudulosum, espécie desprovida de raios fusionados.

Do ponto de vista anatômico, a presença e/ ou abundância de certos tecidos ou células in- 
fluencia diretamente nas propriedades mecânicas da madeira (Burger \& Richter, 1991). Nesse sentido, o lenho de Tetrochidium rubrivenium, composto por elevada porcentagem de tecidos parenquimáticos, além de poros de grande diâmetro e fibras de paredes delgadas a espessas, explicam a baixa massa específica, de sua madeira. Devido a essa densidade básica, Guma (2013) considera a madeira indicada para fabricação de móveis, chapas aglomeradas, caixotaria e embalagens em geral, bem como para confecção de objetos de decoração, acabamento interno e brinquedos.

\section{REFERÊNCIAS BIBLIOGRÁFICAS}

BACKES, P.; IRGANG, B. Mata Atlântica: as árvores e a paisagem. Porto Alegre: Paisagem do Sul, 2004. 396 p.

BARRICHELO, L.E.G.; FOELKEL, C.E.B. Processo nítrico-acético para maceração de madeira. Silvicultura, n. 28, p. 732-733, 1983.

BARROS,C.F; CALLADO, C.H Madeiras da Mata Atlântica. Anatomia do lenho de espécies ocorrentes nos remanescentes florestais do estado do Rio de Janeiro, Brasil. Rio de Janeiro: Instituto de Pesquisas Jardim Botânico do Rio de Janeiro, 1997. 86 p.

BARROS,C.F; CALLADO, C.H.; MARCON M.L.; COSTA, C.G. CUNHA, M.; LIMA, H.R.P.; MARQUETE, O. Madeiras da Mata Atlântica. Anatomia do lenho de espécies ocorrentes nos remanescentes florestais do estado do Rio de Janeiro, Brasil. Rio de Janeiro: Instituto de Pesquisas Jardim Botânico do Rio de Janeiro, $2001.94 \mathrm{p}$.

BARROS,C.F; CALLADO, C.H.; CUNHA, M.; MARCON M.L.F; TAMAIO, N; MARQUETE, O. COSTA, C.G. Madeiras da Mata Atlântica. Anatomia do lenho de espécies ocorrentes nos remanescentes florestais do estado do Rio de Janeiro, Brasil. Rio de Janeiro: Instituto de Pesquisas Jardim Botânico do Rio de Janeiro, 2003. $86 \mathrm{p}$.

BURGER, L.M., RICHTER, H.G. Anatomia da Madeira. São Paulo: Ed. Nobel, 1991. 154 p.

GUMA, R. Propriedades tecnológicas da madeira de Tetrorchidium rubrivenium Poeppig \& Endlicher. 62 f. Dissertação (Mestrado em
Engenharia Florestal) - Universidade Federal de Santa Maria. Santa Maria, 2013.

IAWA - International Association of Wood Anatomists. IAWA list of microscopic features for Hardwood identificacion. IAWA Bulletin, v. 10, n. 3, p. 218-359, 1989.

JUDD, W.S.; CAMPBELL, E.S.; KELLOGG, E.A.; STEVENS, P.F; DONOGHUE, M.J. Sistemática vegetal: um enfoque filogenético. Porto Alegre: Artmed, 2009. p. 355-359.

LORENZI, H.E. Árvores brasileiras: manual de identificação e cultivo de plantas arbóreas nativas do Brasil, Nova Odessa, Instituto Plantarum. 2009. v.3. p. 385.

MAINIERI, C. CHIMELO, J.P. Fichas de características das madeiras brasileiras. São Paulo: Instituto de Pesquisas Tecnológicas, Divisão de Madeiras. 1989. $2^{\text {a }}$ ed. p.418.

MARCHIORI, J.N.C. Estudo anatômico do xilema secundário e da casca de algumas espécies dos gêneros Acacia e Mimosa, nativas no estado do Rio Grande do Sul. 186 f. Dissertação (Mestrado em Engenharia Florestal). Curitiba: Universidade Federal do Paraná, 1980.

MARCHIORI, J.N.C. Dendrologia das Angiospermas: das Bixáceas às Rosáceas. Santa Maria: Ed. UFSM, 2000. 240p.

MARCHIORI, J.N.C.; MUNIZ, G.I.E. de; SANTOS, S.R. dos. Madeiras do Rio Grande do Sul. 1. Descrição microscópica de 33 espécies nativas. Santa Maria: Anaterra, 2009. 80 p.

MARCHIORI, J.N.C.; MUNIZ, G.I.B.; SANTOS, S.R. dos. Madeiras do Rio Grande do Sul: descrição microscópica de 35 espécies nativas. Santa Maria: Anaterra, 2010. v. 2. 80p.

MENNEGA, A.M.W. Wood anatomy of the subfamily Euphorbioideae. A comparison with subfamilies Crotonoideae and Acalyphoideae and the implications for the circumscription of the Euphorbiaceae. IAWA Bulletin, v. 26, n. 1, p. 1-68, 2005.

METCALFE, C.R.; CHALK, L. Anatomy of the Dicotyledons. Oxford: Clarendon Press, 1972. p.1207-1235.

POEPPIG, E. Nova Genera et Species Plantarum: in regno chilensi peruviano et in terra amazonica. Lipsiae, Germany: Frederici Hofmeister, 1845.

RECORD, S.L; HESS, R.W. Timbers of the New World. New Haven: Yale University Press, 1949. $640 \mathrm{p}$. 
REITZ, R.; KLEIN, R.M.; REIS, A. Projeto Madeira do Rio Grande do Sul. Porto Alegre: Governo do estado do Rio Grande do Sul, 1988. 528p.

RUSCHEL, A.P.; GUERRA, M.P.; MOERSCHBACHER, B.M.; NODARI, R.O. Valuation and characterization of the timber species in remnants of the Alto Uruguay River ecosystem, Southern Brazil. Forest Ecology and Management, v. 217, p. 103-116, 2005.

SIEGLOCH, M.A.; SANTOS, R.S.; MARCHIORI, J.N.C. Estudo anatômico do lenho de Colliguaya brasiliensis Klotzsch ex Baill. (Euphorbiaceae). Balduinia, n. 27, p. 27-33, 2011.

SIEGLOCH, M.A.; MARCHIORI, J.N.C.; SANTOS, R.S. Anatomia do lenho de Bernardia pulchella (Euphorbiaceae). Balduinia. n. 34, p. 28-32, 2012.

SIEGLOCH, M.A.; MARCHIORI, J.N.C.; SANTOS, R.S. dos. Anatomia da madeira de dezesseis espécies de Euphorbiaceae lato sensu, com base na análise de agrupamento de caracteres anatômicos. Balduinia. n. 40, p. 0917, 2013.

SOUZA, V.C.; LORENZI, H. Botânica Sistemática: guia ilustrado para identificação das famílias de Angiospermas da flora brasileira, baseado em APG 1I. Nova Odessa: Instituto Plantarum, 2005. 640p.

WEBSTER, G.L. Annals of the Missouri Botanical Garden, St. Louis, v.81, n.1, 1994. 